\title{
Oncological Outcomes following Rectal Cancer Surgery with High or Low Ligation of the Inferior Mesenteric Artery
}

\author{
Kenji Matsuda Shozo Yokoyama Tsukasa Hotta Katsunari Takifuji \\ Takashi Watanabe Koichi Tamura Yasuyuki Mitani Hiromitsu Iwamoto \\ Yuki Mizumoto Hiroki Yamaue \\ Second Department of Surgery, School of Medicine, Wakayama Medical University, \\ Wakayama, Japan
}

\section{Keywords}

High or low ligation · Inferior mesenteric artery $\cdot$ Rectal cancer

\begin{abstract}
Background: The level of inferior mesenteric artery (IMA) ligation for anterior resection of rectal cancer has several considerations concerning oncological outcomes. The primary endpoint of this randomized controlled trial (RCT) was to assess bowel function between high and low ligation. This study was intended to clarify oncological outcome as the secondary endpoint. Objective: The aim of this study was to assess in a prospective RCT whether the ligation level of the IMA in rectal cancer influences oncological outcomes. Methods: Between February 2008 and December 2011, 100 patients who underwent anterior resection for rectal cancer were randomized to perform either high or low ligation of the IMA. Oncological outcomes was the secondary endpoint of this RCT, whereas assessing bowel function was the primary endpoint. This RCT was registered at clinicaltrials.gov (NCT00701012). Results: There were no differences between the groups in terms of clinical data except for tumor stage. There were more advanced-stage patients in the high ligation group $(p=0.046)$. There were no lymph node (LN) metastases in the root of the IMA in the high ligation group. The average number of harvested LNs for the high and low ligation groups was 16.7 and 14.9, respectively. There was no difference in disease-free survival (DFS), site of first recurrence, and overall survival (OS). When patients were in stage III, there was also no difference in DFS and OS. Conclusions: The ligation level of the IMA in rectal cancer may not influence oncological outcomes. However, further large-scale RCTs are needed to conclude this issue.

(c) 2017 S. Karger AG, Basel
\end{abstract}




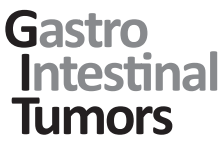

Introduction

\begin{tabular}{l|l}
\hline \multicolumn{2}{l}{ Gastrointest Tumors 2017:4:45-52 } \\
\hline DOI: 10.1159/000477805 & $\begin{array}{l}\text { @ 2017 S. Karger AG, Basel } \\
\text { www.karger.com/gat }\end{array}$ \\
\hline
\end{tabular}

Matsuda et al.: Oncological Outcomes following Rectal Cancer Surgery with High or Low Ligation of the Inferior Mesenteric Artery

In rectal cancer surgery, the optimal ligation level of the inferior mesenteric artery (IMA) has always been discussed. Extended lymph node (LN) dissection is not accepted worldwide in colorectal cancer surgery as there is no evidence that radical LN dissection leads to better survival. However, high ligation of the IMA in rectal cancer surgery is recommended if the clinical tumor depth is more than T2 or if clinical LN metastases are present according to the Japanese guidelines [1]. Apical LN dissection around the root of the IMA is still an interesting issue $[2,3]$. This is because LN metastases exist around the root of the IMA, the reported incidence ranging from 0.3 to $14.2 \%$ [4-11]. Japanese surgeons believe that $L N$ dissection in this area is beneficial. On the other hand, guidelines in the USA recommend low ligation in most rectal cancer cases [12]. Surgeons in the USA feel that there is no high incidence of LN metastases around the root of the IMA.

There are several considerations other than oncological concerning the level of IMA ligation, such as anatomical, technical, and functional aspects [13-16]. There is a possibility that high ligation is preferable for anastomotic tension, while low ligation is preferable regarding postoperative bowel, urinary, and sexual function. It is possible that high ligation allows more accurate tumor staging because of the increased number of examined LNs [17]. While several papers have reported on the ligation level of the IMA, there has been no randomized controlled trial (RCT) studying oncological outcomes.

We have reported the findings of our randomized clinical trial on bowel function following anterior resection for rectal cancer with high or low ligation of the IMA [18]. From that RCT, we reported that high ligation of the IMA does not affect bowel function following anterior resection for rectal cancer. As for the secondary endpoints, we also reported findings related to postoperative complications such as anastomotic leakage. In this report, we tried to show data concerning oncological outcomes and examined LN distribution. The aim of this study was to demonstrate whether high ligation of the IMA is more beneficial compared to low ligation in terms of survival rate.

\section{Patients and Methods}

Inclusion and Exclusion Criteria

Between February 2008 and December 2011, an RCT was conducted at Wakayama Medical University Hospital to compare high or low ligation of the IMA in patients with rectal cancer [18]. Inclusion criteria were as follows: patients with curable rectal cancer located $<15 \mathrm{~cm}$ from the anus and patients with end to end anastomosis reconstructed by the double-stapling technique (DST). A total of 113 eligible patients were entered into this study before operation. Patients with resectable distant metastases were assigned to simultaneous or metachronous metastatic site resection. Informed consent was received from all patients, who also agreed to at least a 3-year postoperative follow-up. Patients were randomized intraoperatively to high or low ligation of the IMA once the surgeon had determined to perform anterior resection with reconstruction by the DST. Exclusion criteria were as follows: tumor situated $>15 \mathrm{~cm}$ from the anus, patients with unresectable metastatic disease, patients with suspected LN metastases at the root of the left colic artery (LCA), and patients with early-stage disease (clinical Tis and T1). This study was approved by the ethical committee of Wakayama Medical University Hospital and registered at clinicaltrials.gov (NCT00701012).

Surgical Management and Follow-Up

High ligation was at the root of the aorta while low ligation was just distal from the root of the LCA. Tumor location was defined by colonoscopy as follows: low $(<5 \mathrm{~cm})$, middle $(5-10 \mathrm{~cm})$, and upper (11$15 \mathrm{~cm}$ ). Patients with middle and low rectal cancer received total mesorectal excision, while upper rectal cancer patients underwent tumor-specific mesorectal excision. The proximal transected line was $10 \mathrm{~cm}$ from the tumor, according to the Japanese guidelines. All patients' anastomoses were reconstructed by end to end 
Gastro

Intestinal

Tumors

Table 1. Clinical data of 100 randomized patients

\begin{tabular}{l|l}
\hline \multicolumn{2}{l}{ Gastrointest Tumors 2017:4:45-52 } \\
\hline DOI: 10.1159/000477805 & $\begin{array}{l}\text { @ 2017 S. Karger AG, Basel } \\
\text { www.karger.com/gat }\end{array}$ \\
\hline
\end{tabular}

Matsuda et al.: Oncological Outcomes following Rectal Cancer Surgery with High or Low Ligation of the Inferior Mesenteric Artery

\begin{tabular}{|c|c|c|c|}
\hline Category & $\begin{array}{l}\text { High ligation } \\
(n=51)\end{array}$ & $\begin{array}{l}\text { Low ligation } \\
(n=49)\end{array}$ & $\begin{array}{l}p \\
\text { value }\end{array}$ \\
\hline Median age & 69 & 67 & 0.696 \\
\hline Sex (male/female) & $33 / 18$ & $34 / 15$ & 0.619 \\
\hline \multicolumn{4}{|l|}{ Tumor location } \\
\hline Upper & 15 & 15 & \multirow[t]{3}{*}{0.863} \\
\hline Middle & 20 & 21 & \\
\hline Lower & 16 & 13 & \\
\hline \multicolumn{4}{|l|}{ Tumor stage (TNM) } \\
\hline 0 & 2 & 0 & \multirow[t]{5}{*}{0.046} \\
\hline I & 7 & 17 & \\
\hline II & 15 & 17 & \\
\hline III & 23 & 13 & \\
\hline IV & 4 & 2 & \\
\hline \multicolumn{4}{|l|}{ Type of surgery } \\
\hline Laparoscopic/open & $40 / 11$ & $44 / 5$ & 0.121 \\
\hline \multicolumn{4}{|c|}{ Lateral pelvic lymph node dissection } \\
\hline Yes/no & $8 / 43$ & $7 / 42$ & 0.845 \\
\hline \multicolumn{4}{|l|}{ Preoperative CRT } \\
\hline Yes/no & $2 / 49$ & $5 / 44$ & 0.202 \\
\hline \multicolumn{4}{|l|}{ ASA score } \\
\hline$\geq 3 / \leq 2$ & $4 / 47$ & $4 / 45$ & 0.620 \\
\hline \multicolumn{4}{|l|}{ Blood loss, mL } \\
\hline Median (range) & $30(0-1,050)$ & $20(0-720)$ & 0.190 \\
\hline \multicolumn{4}{|l|}{ Surgical time, min } \\
\hline Median (range) & $265(124-502)$ & $247(118-526)$ & 0.402 \\
\hline \multicolumn{4}{|c|}{ Postoperative chemotherapy } \\
\hline Yes/no & $29 / 22$ & $20 / 29$ & 0.109 \\
\hline Site of first recurrence ${ }^{1}$ & & & 0.292 \\
\hline Liver & 3 & 7 & \\
\hline Lung & 5 & 2 & \\
\hline Local & 3 & 2 & \\
\hline Peritoneum & 1 & 0 & \\
\hline Lymph node & 1 & 0 & \\
\hline \multicolumn{4}{|c|}{ Mean number of harvested lymph nodes } \\
\hline Total lymph nodes & 16.7 & 14.9 & 0.119 \\
\hline Group 1 nodes & 9.2 & 9.2 & \\
\hline Group 2 nodes & 4.1 & 3.8 & \\
\hline Group 3 nodes & 1.5 & NA & \\
\hline Lateral nodes ${ }^{2}$ & 11.9 & 13.6 & \\
\hline
\end{tabular}

ASA, American Society of Anesthesiologists; CRT, chemoradiation therapy; group 1 nodes, pararectal nodes; group 2 nodes, inferior mesenteric trunk nodes; group 3 nodes, inferior mesenteric root nodes; NA, not available; TNM, Tumor Nodes Metastasis. ${ }^{1}$ Thirteen sites in 12 patients in high ligation and 11 sites in 9 patients in low ligation. ${ }^{2}$ Number of lymph nodes in 15 patients ( 8 in the high ligation and 7 in the low ligation group) with lateral pelvic lymph node dissection.

anastomosis using the DST. Laparoscopic surgery for advanced rectal cancer was started in 2009, and preoperative chemoradiation therapy was introduced in 2010 for advanced middle and low rectal cancer patients. Lateral pelvic LN dissection was done for low rectal cancer patients with above T3 tumor and LN metastases in the mesorectum. The regional LNs classified by the Japanese guidelines are as follows: group 1, nodes adjacent to the rectal wall; group 2, nodes along the IMA trunk distal to the LCA; group 3, nodes around the root of the IMA. Pathological stage II and III patients underwent postoperative adjuvant oral 5-FU-based chemotherapy, and 5-FU- and oxaliplatin-based chemotherapy was performed in stage III patients with massive LN metastases and in stage IV patients. 
Matsuda et al.: Oncological Outcomes following Rectal Cancer Surgery with High or Low Ligation of the Inferior Mesenteric Artery

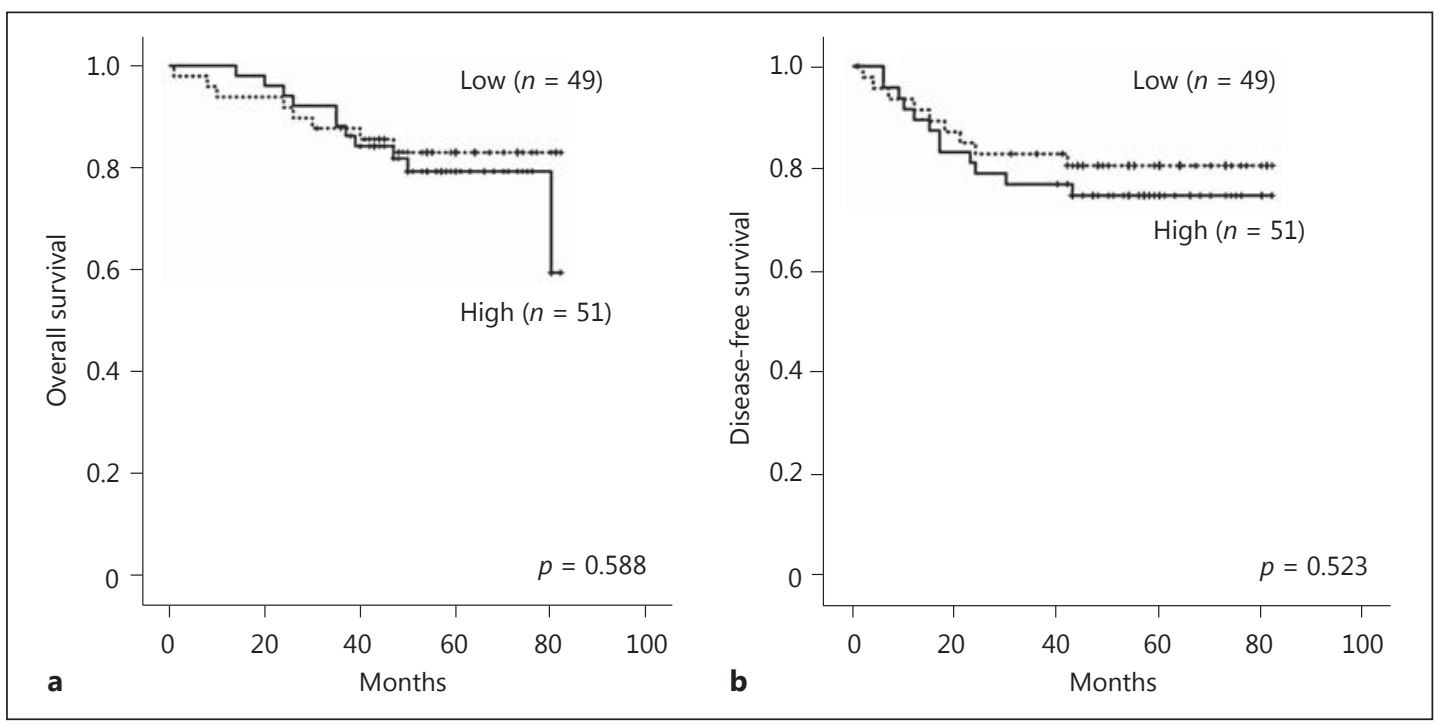

Fig. 1. a Cumulative overall survival rates in patients with high ligation (solid line) and low ligation (dotted line). There is no difference between the two groups $(p=0.588)$. $\mathbf{b}$ Cumulative disease-free survival rates in patients with high ligation (solid line) and low ligation (dotted line). There is no difference between the two groups ( $p=0.523)$.

The endpoints of this analysis were to show the examined LN status and oncological outcomes. All patients received postoperative surveillance using computed tomography every 6 months, carcinoembryonic antigen level every 3 months, and colonoscopy within 1 year of surgery.

\section{Statistical Analyses and Sample Size Calculation}

The number of patients in this study was designed to evaluate postoperative bowel function, but not postoperative morbidity and survival rate. The details were the same as previously described [18]. Comparative analyses were performed using the $\chi^{2}$ test, the Fisher exact test, and the Mann-Whitney U test for numerical data. Differences in overall survival (OS) and disease-free survival (DFS) were assessed using the Kaplan-Meier method. The findings were compared for significance by log-rank test. The SPSS software statistical package was used for analysis (SPSS 19.0 for Windows, SPSS Inc., Chicago, IL, USA). Statistical significance was defined as $p<0.05$.

\section{Results}

A total of 113 patients with rectal cancer were enrolled and 100 patients were randomized in this trial, 51 being allocated to high ligation and 49 to low ligation between February 2008 and December 2011. Thirteen patients were excluded from this trial due to suspected LN metastases at the root of the LCA $(n=5)$, detection of unresectable peritoneal metastases intraoperatively $(n=2)$, inability to undergo DST $(n=3)$, and refusal to participate $(n=3)$. There was no 30-day mortality in both groups.

Tumor status as well as pre- and postoperative information are shown in Table 1. The two groups did not differ significantly, except for final tumor staging $(p=0.046)$. There were no differences between the two groups regarding the performance of postoperative adjuvant chemotherapy $(p=0.109)$.

The median follow-up period in this study was 54 months (range, 1-82 months). There were 12 recurrent patients in the high ligation and 9 patients in the low ligation group. There 


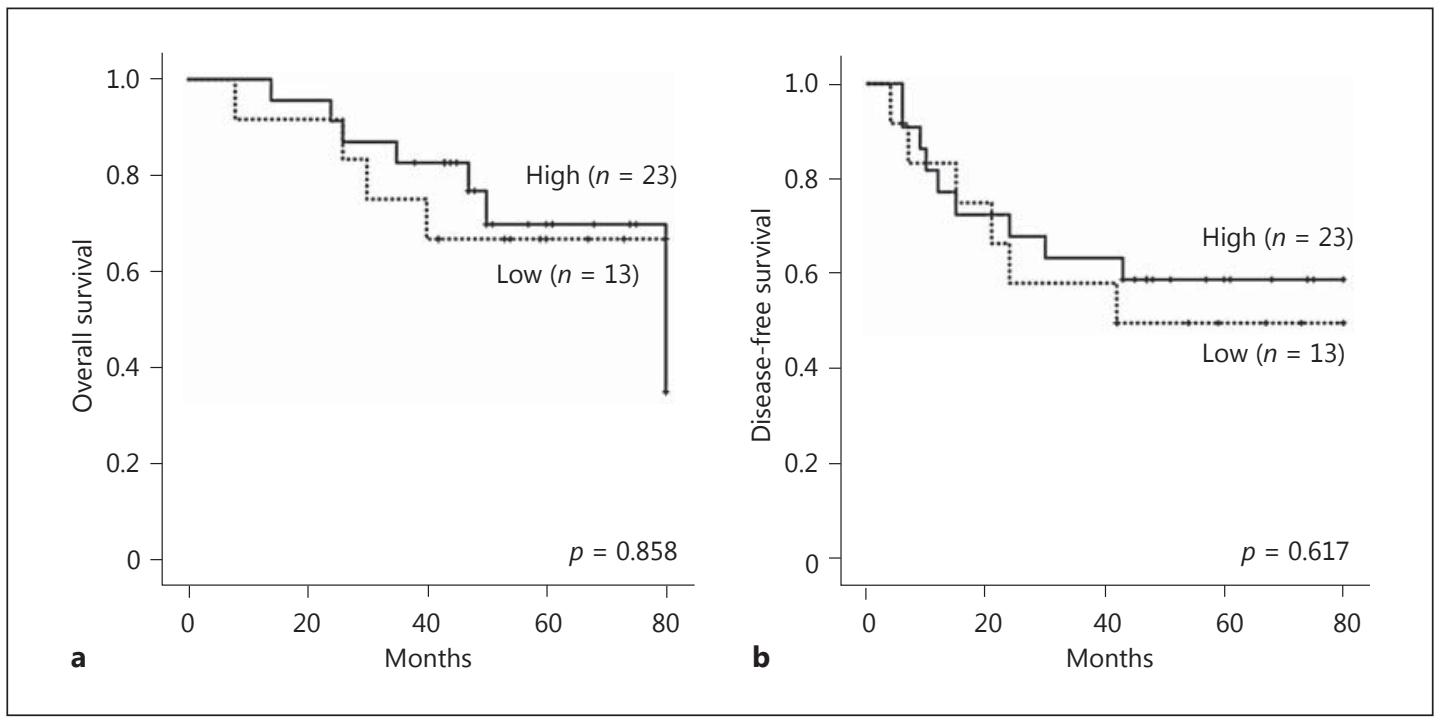

Fig. 2. a Cumulative overall survival rates in stage III patients with high ligation (solid line) and low ligation (dotted line). There is no difference between the two groups $(p=0.858)$. $\mathbf{b}$ Cumulative disease-free survival rates in stage III patients with high ligation (solid line) and low ligation (dotted line). There is no difference between the two groups ( $p=0.617)$.

was no difference in the site of first recurrence between the two groups ( $p=0.292)$. There was no difference in the number of harvested LNs in group 1 and group 2 nodes. Furthermore, there was no difference in the total number of harvested LNs between the two groups $(p=$ $0.119)$. The average number of harvested LNs around the root of the IMA was 1.5 in the high ligation group.

There was no difference in OS and DFS rate between the groups (Fig. 1). The 5-year DFS and OS of high ligation was 74.9 and $79.3 \%$, respectively. The 5 -year DFS and OS of low ligation was 80.7 and $83.0 \%$, respectively. Furthermore, when patients were in stage III, we could not find differences in OS and DFS rates between the two groups (Fig. 2).

\section{Discussion}

In rectal cancer surgery, the level of IMA ligation has always been debated $[5,7,10,19$, 20]. Although dividing the IMA is a tiny issue for rectal cancer surgery, there is still no consensus. The optimal ligation level should be demonstrated in light of several considerations, especially in light of oncological outcomes.

There have been several publications on high or low ligation of the IMA in rectal cancer surgery. However, none has indicated that high ligation is definitely associated with significantly better long-term survival [13-16]. Most of the papers supporting high ligation have shown that substantial LN metastases around the root of the IMA truly exist, ranging from 0.3 to $14.2 \%$ (Table 2). They claim that resection lead to better survival $[5,7,8]$. On the contrary, most studies which supported low ligation claim that incidence of LN metastases around the root of the IMA is rare. Furthermore, when patients have such LN metastases, the 5-year survival rate is relatively low, ranging from 0 to $40 \%$. The authors believe that resection of such LNs does not lead to longer survival as they speculate that once the tumor is involved in these apical LNs, it may have potentially metastasized systemically $[4,10,17]$. It has also been 
Matsuda et al.: Oncological Outcomes following Rectal Cancer Surgery with High or Low Ligation of the Inferior Mesenteric Artery

Table 2. Summary of data on the lymph node metastases around the root of the inferior mesenteric artery

\begin{tabular}{|c|c|c|c|c|c|c|c|}
\hline $\begin{array}{l}\text { Reference } \\
\text { (first author) }\end{array}$ & $\begin{array}{l}\text { Patients, } \\
n\end{array}$ & $\begin{array}{l}\text { Metastatic } \\
\text { rate around } \\
\text { the root of } \\
\text { the IMA }\end{array}$ & $\begin{array}{l}\text { Tumor } \\
\text { depth or } \\
\text { stage }\end{array}$ & $\begin{array}{l}\text { Tumor } \\
\text { location }\end{array}$ & $\begin{array}{l}5 \text {-year } \\
\text { survival } \\
\text { rate in } \\
\text { IMA LN (+) }\end{array}$ & $\begin{array}{l}\text { Exclu- } \\
\text { sion }\end{array}$ & $\begin{array}{l}\text { Mean } \\
\text { harvested } \\
\text { LNs, } n\end{array}$ \\
\hline Adachi [4], 1998 & 172 & $0.7 \%$ & $\geq \mathrm{T} 1$ & $\mathrm{~S}$ and $\mathrm{R}$ & - & DM & - \\
\hline Hida [5], 1998 & 198 & $8.6 \%$ & $\geq \mathrm{T} 1$ & $\mathrm{R}$ & $\begin{array}{l}38.5 \% \text { (only } \\
\text { curative case) }\end{array}$ & none & 73.5 \\
\hline Huh [6], 2012 & 1,205 & $7.8 \%$ & $\geq \mathrm{T} 1$ & $\mathrm{~S}$ and $\mathrm{R}$ & $28 \%$ & $\mathrm{NC}$ & - \\
\hline Kanemitsu [7], 2006 & 1,188 & $1.7 \%$ & $\geq \mathrm{T} 1$ & $\mathrm{~S}$ and $\mathrm{R}$ & $40 \%$ & $\mathrm{NC}$ & 28.6 \\
\hline Liang [8], 2007 & 98 & $14.2 \%$ & stage III & S and upper $\mathrm{R}$ & - & DM & 27.4 \\
\hline Steup [9], 2002 & 605 & $0.3 \%$ & $\geq \mathrm{T} 1$ & $\begin{array}{l}\text { middle and } \\
\text { low } \mathrm{R}\end{array}$ & - & $\mathrm{NC}$ & 32.8 \\
\hline Uehara [10], 2007 & 285 & $1.4 \%$ & $\begin{array}{l}\text { stage II } \\
\text { and III }\end{array}$ & $\begin{array}{l}\leq 7 \mathrm{~cm} \text { from } \\
\text { dentate line }\end{array}$ & $0 \%$ & DM & 42.0 \\
\hline Ueno [11], 2007 & 244 & $3.1 \%$ & $\geq \mathrm{T} 2$ & $\begin{array}{l}\text { tumor edge } \\
\text { below peritoneal } \\
\text { reflection }\end{array}$ & $\begin{array}{l}14.3 \% \\
\text { (cancer- } \\
\text { specific) }\end{array}$ & DM & - \\
\hline
\end{tabular}

DM, distant metastases; IMA, inferior mesenteric artery; LN, lymph node; NC, not curative; R, rectum; S, sigmoid.

reported that the survival benefit of dissecting around the root of the IMA is extremely low compared to other areas such as the mesorectum and the lateral pelvic area.

In this study, we excluded 5 patients because of suspected LN metastases around the root of the LCA. Among these cases, 2 had LN metastases around the root of the IMA. However, these 2 patients developed recurrence soon after the operation in spite of dissection of the LNs around the root of the IMA. One developed liver metastases 10 months after surgery, while the other developed pelvic LN recurrence 2 months after surgery. Thus, in our limited cases there might be no survival benefit in performing dissection of LNs around the root of the IMA.

There is an anatomical consideration. It is hypothesized that low ligation keeps an adequate blood flow to the proximal colon of anastomosis. On the other hand, high ligation is reported to reduce the blood supply to the proximal limb, especially in older male patients [21]. In our previous report, although there were no significant differences between the two groups in terms of symptomatic anastomotic leakage and anastomotic stricture rates, the incidence of anastomotic leakage was $6 \%$ higher in the high ligation group [18]. If we conduct a large-scale RCT, significant difference may be demonstrated. Tension-free anastomosis is required to avoid anastomotic leakage. Although the gain in colonic length was longer in high compared to low ligation, low ligation can be safely performed for anastomosis in rectal cancer surgery in most cases $[22,23]$. In this analysis, there was no patient in the low ligation group requiring division of the LCA because of anastomotic tension.

Although there may be no survival benefit, it has been reported that the examined number of LNs increased when the apical LNs were dissected $[10,17]$. In our report, the increased mean number of LNs was 1.8, with no significant difference in the total number of LNs between the groups ( $p=0.119$ ). In the high ligation group, more advanced cases were observed. The cause of this finding is not clear. It may be a stage migration phenomenon or it may be due to 
Matsuda et al.: Oncological Outcomes following Rectal Cancer Surgery with High or Low Ligation of the Inferior Mesenteric Artery

the small number of patients. However, a large number of patients is required to assess the stage migration phenomenon.

There is a limitation to this study. As this RCT was conducted to assess postoperative bowel function, the number of patients was not calculated to assess oncological outcomes. To overcome this limitation, a future RCT is needed in order to draw a definitive conclusion on the oncological outcomes. The incidence of LN metastases around the IMA is low, and if we conduct a RCT, a large number of patients will be required. Therefore, it may be difficult to conduct such a RCT.

In conclusion, this study has shown that high and low ligation following anterior resection for rectal cancer have similar oncological outcomes. In patients without massive LNs around the root of the IMA, we recommend low ligation in rectal cancer surgery.

\section{Disclosure Statement}

None of the authors has any conflict of interest.

\section{Author Contributions}

Study conception and design: K. Matsuda, S. Yokoyama, H. Yamaue. Acquisition of data: K. Matsuda, T. Watanabe, K. Tamura, Y. Mitani, H. Iwamoto, Y. Mizumoto. Analysis and interpretation of data: K. Matsuda, T. Hotta, K. Takifuji, H. Yamaue. Drafting of the manuscript: K. Matsuda, S. Yokoyama, T. Hotta. Critical revision: S. Yokoyama, K. Takifuji, H. Yamaue. Supervision: H. Yamaue.

\section{References}

1 Watanabe T, Itabashi M, Shimada Y, Tanaka S, Ito Y, Ajioka Y, Hamaguchi T, Hyodo I, Igarashi M, Ishida H, Ishiguro M, Kanemitsu Y, Kokudo N, Muro K, Ochiai A, Oguchi M, Ohkura Y, Saito Y, Sakai Y, Ueno H, Yoshino T, Fujimori T, Koinuma N, Morita T, Nishimura G, Sakata Y, Takahashi K, Takiuchi H, Tsuruta O, Yamaguchi T, Yoshida M, Yamaguchi N, Kotake K, Sugihara K; Japanese Society for Cancer of the Colon and Rectum: Japanese Society for Cancer of the Colon and Rectum (JSCCR) guidelines 2010 for the treatment of colorectal cancer. Int J Clin Oncol 2012;17:1-29.

2 Goh N, Fong SS, How KY, Wong KY, Loong TH, Tay GT: Apical lymph node dissection of the inferior mesenteric artery. Colorectal Dis 2016;18:0206-0209.

3 Huang CW, Yeh YS, Su WC, Tsai HL, Choy TK, Huang MY, Huang CM, Wu IC, Hu HM, Hsu WH, Su YC, Wang JY: Robotic surgery with high dissection and low ligation technique for consecutive patients with rectal cancer following preoperative concurrent chemoradiotherapy. Int J Colorectal Dis 2016;31:1169-1177.

4 Adachi Y, Inomata M, Miyazaki N, Sato K, Shiraishi N, Kitano S: Distribution of lymph node metastasis and level of inferior mesenteric artery ligation in colorectal cancer. J Clin Gastroenterol 1998;26:179-182.

5 Hida J, Yasutomi M, Maruyama T, Fujimoto K, Nakajima A, Uchida T, Wakano T, Tokoro T, Kubo R, Shindo K: Indication for using high ligation of the inferior mesenteric artery in rectal cancer surgery. Examination of nodal metastases by the clearing method. Dis Colon Rectum 1998;41:984-987.

6 Huh JW, Kim YJ, Kim HR: Distribution of lymph node metastases is an independent predictor of survival for sigmoid colon and rectal cancer. Ann Surg 2012;255:70-78.

7 Kanemitsu Y, Hirai T, Komori K, Kato T: Survival benefit of high ligation of the inferior mesenteric artery in sigmoid colon or rectal cancer surgery. Br J Surg 2006; 93:609-615.

8 Liang JT, Huang KC, Lai HS, Lee PH, Sun CT: Oncologic results of laparoscopic D3 lymphadenectomy for male sigmoid and upper rectal cancer with clinically positive lymph nodes. Ann Surg Oncol 2007;14:1980-1990.

9 Steup WH, Moriya Y, van de Velde CJ: Patterns of lymphatic spread in rectal cancer. A topographical analysis on lymph node metastases. Eur J Cancer 2002;38:911-918.

10 Uehara K, Yamamoto S, Fujita S, Akasu T, Moriya Y: Impact of upward lymph node dissection on survival rates in advanced lower rectal carcinoma. Dig Surg 2007;24:375-381.

11 Ueno H, Mochizuki H, Hashiguchi Y, Ishiguro M, Miyoshi M, Kajiwara Y, Sato T, Shimazaki H, Hase K: Potential prognostic benefit of lateral pelvic node dissection for rectal cancer located below the peritoneal reflection. Ann Surg 2007;245:80-87. 
12 Nelson H, Petrelli N, Carlin A, Couture J, Fleshman J, Guillem J, Miedema B, Ota D, Sargent D: Guidelines 2000 for colon and rectal cancer surgery. J Natl Cancer Inst 2001;93:583-596.

13 Cirocchi R, Trastulli S, Farinella E, Desiderio J, Vettoretto N, Parisi A, Boselli C, Noya G: High tie versus low tie of the inferior mesenteric artery in colorectal cancer: a RCT is needed. Surg Oncol 2012;21:e111-e123.

14 Hida J, Okuno K: High ligation of the inferior mesenteric artery in rectal cancer surgery. Surg Today 2013;43: 8-19.

15 Lange MM, Buunen M, van de Velde CJ, Lange JF: Level of arterial ligation in rectal cancer surgery: low tie preferred over high tie. A review. Dis Colon Rectum 2008;51:1139-1145.

16 Titu LV, Tweedle E, Rooney PS: High tie of the inferior mesenteric artery in curative surgery for left colonic and rectal cancers: a systematic review. Dig Surg 2008;25:148-157.

17 Kawamura YJ, Umetani N, Sunami E, Watanabe T, Masaki T, Muto T: Effect of high ligation on the long-term result of patients with operable colon cancer, particularly those with limited nodal involvement. Eur J Surg 2000;166:803-807.

18 Matsuda K, Hotta T, Takifuji K, Yokoyama S, Oku Y, Watanabe T, Mitani Y, Ieda J, Mizumoto Y, Yamaue H: Randomized clinical trial of defaecatory function after anterior resection for rectal cancer with high versus low ligation of the inferior mesenteric artery. Br J Surg 2015;102:501-508.

19 Corder AP, Karanjia ND, Williams JD, Heald RJ: Flush aortic tie versus selective preservation of the ascending left colic artery in low anterior resection for rectal carcinoma. Br J Surg 1992;79:680-682.

20 Surtees P, Ritchie JK, Phillips RK: High versus low ligation of the inferior mesenteric artery in rectal cancer. $\mathrm{Br}$ J Surg 1990;77:618-621.

21 Seike K, Koda K, Saito N, Oda K, Kosugi C, Shimizu K, Miyazaki M: Laser Doppler assessment of the influence of division at the root of the inferior mesenteric artery on anastomotic blood flow in rectosigmoid cancer surgery. Int J Colorectal Dis 2007;22:689-697.

22 Bonnet S, Berger A, Hentati N, Abid B, Chevallier JM, Wind P, Delmas V, Douard R: High tie versus low tie vascular ligation of the inferior mesenteric artery in colorectal cancer surgery: impact on the gain in colon length and implications on the feasibility of anastomoses. Dis Colon Rectum 2012;55:515-521.

23 Buunen M, Lange MM, Ditzel M, Kleinrensink GJ, van de Velde CJ, Lange JF: Level of arterial ligation in total mesorectal excision (TME): an anatomical study. Int J Colorectal Dis 2009;24:1317-1320. 